\title{
Concepções de professoras colombianas sobre a profissão docente: significados, escolhas e exercício profissional
}

\section{Conceptions of colombian teachers about the teaching profession: meanings, choices and professional practice.}

\section{Concepciones de profesoras colombianas sobre la profesión docente; significados, elecciones y ejercicio profesional.}

Edmila de Oliveira ${ }^{1}$

Denise Barreto ${ }^{2}$

\begin{abstract}
Resumo
O presente estudo analisa as concepções de um grupo de professoras colombianas acerca da profissão docente. $\mathrm{O}$ percurso metodológico trilhado para a produção e coleta de dados se caracterizou por uma abordagem qualitativa, tendo como técnica a conversa interativoprovocativa, criada e utilizada por Nunes (2011). Foram coletadas narrativas de seis professoras atuantes num Instituto de Ensino primário, na cidade de Ibagué-TolimaColômbia. A análise dos dados possibilitou o destaque de três categorias: "significados de ser professora", "a escolha profissional" e "a vocação para o exercício da profissão docente". A partir das reflexões propostas no estudo, ficou evidente a necessidade de (re) pensar a profissionalização docente para além da visão do professor como sacerdote ou dotado de um dom para lecionar. A ênfase recai na importância do processo ininterrupto de formação que contribui de maneira significativa para a construção da identidade profissional e pessoal, bem como para o exercício de profissionais comprometidos com uma Educação de qualidade.
\end{abstract}

Palavras-chave: Profissão docente; Exercício profissional; Vocação; Profissionalização.

\begin{abstract}
This study analyzes the conceptions of a group of Colombian teachers about the teaching profession. The methodological path followed for the production and collection of data was characterized by a qualitative approach, having as a technique the interactive-provocational conversation, created and used by Nunes (2011). Narratives were collected from six female teachers working at an Institute of Primary Education in the city of Ibagué, Tolima, Colombia. The data analysis made it possible to highlight three categories: "meanings of being a teacher", "the professional choice" and "the vocation for exercising the teaching profession". From the reflections proposed in the study, it became clear the need to (re) think

\footnotetext{
${ }^{1}$ Mestra em Educação - UESB - Licenciada em Pedagogia e em Letras - email: edmilaoliveira@hotmail.com ${ }^{2}$ Doutora em Educação - FACED/UFBA -Pós-doutora em Educação - FPCE/ Universidade de Coimbra Professora Titular da Universidade Estadual do Sudoeste da Bahia - UESB -Programa de Pós-graduação em Educação - PPGED/UESB -email: deniseabrito@gmail.com . ORCID: https://orcid.org/0000-0003-3448-5109
} 
about teaching professionalization beyond the vision of the teacher as a priest or provided with a gift for teaching. The emphasis is on the importance of the uninterrupted process of formation that contributes significantly to the construction of professional and personal identity, as well as to the exercise of professionals committed to a quality Education.

Keywords: Teaching profession; Professional exercise; Vocation; Professionalization.

\section{Resumen}

Este estudio analiza las concepciones de un grupo de profesoras colombianas sobre la profesión docente. La trayectoria metodológica seguida para la producción y recopilación de datos se caracterizó por un enfoque cualitativo, utilizando como técnica la conversación interactiva-provocativa, creada y utilizada por Nunes (2011). Se recogieron los relatos de seis profesoras que trabajaban en un Instituto de Educación Primaria de la ciudad de Ibagué, Tolima, Colombia. El análisis de los datos permitió destacar tres categorías: "el significado de ser profesor", "la elección profesional" y "la vocación de ejercer la profesión docente". A partir de las reflexiones propuestas en el estudio, se hizo evidente la necesidad de (re) pensar en la profesionalización de la enseñanza más allá de la visión del profesor como sacerdote o provisto de un don para la enseñanza. Se hace hincapié en la importancia del proceso ininterrumpido de capacitación que contribuye de manera significativa a la construcción de la identidad profesional y personal, así como al ejercicio de profesionales comprometidos con una Educación de calidad.

Palabras clave: Profesión docente; Ejercicio profesional; Vocación; Profesionalización.

\section{Considerações Iniciais}

Pesquisas realizadas acerca das concepções dos professores sobre o significado e exercício docente (LIBÂNEO, 1998; NÓVOA, 1999; ARROYO, 2000; GADOTTI, 2003) atestam o interesse por estudos no campo da formação de docente e seus desdobramentos. Essas temáticas apontam que investigar sobre o "ser professor/a" abrange diversas perspectivas e também trazem à tona demandas pertinentes. Uma dessas demandas é a necessidade de repensar a profissionalização docente, visto que, de acordo com Imbernón (2011, p. 36) "a profissionalização do professor está diretamente ligada ao exercício de sua prática profissional".

Nessa direção, o presente estudo teve como objetivo analisar as concepções de professoras colombianas sobre a profissão docente. Foram desveladas questões referentes aos significados de "ser professor", bem como as motivações para a escolha e para o exercício profissional. De acordo com Dubar (2005) é ao longo de toda a trajetória profissional e 
pessoal dos professores que as concepções sobre ser professor são construídas. Além disso, constrói-se também a identidade docente, a qual perpassa pelos aspectos relacionados ao período escolar, formação inicial e percurso na carreira.

Após a realização de intercâmbio acadêmico em um curso de formação de professores, na Universidad Pedagógica Nacional, em Bogotá, na Colombia, bem como a partir de diálogos com profissionais docentes de escolas primárias do referente país, as pesquisadoras foram motivadas pela seguinte inquietação: quais as concepções das professoras colombianas sobre a profissão docente? Essa questão de pesquisa norteou o presente artigo, que apresenta, com base nos dados obtidos e analisados, questões voltadas para os significados, as escolhas e o exercício profissional.

As seis professoras que fizeram parte da presente investigação trabalhavam num Instituto de Ensino primário, na cidade de Ibagué (Colombia), todas há mais de cinco anos atuantes naquele Instituto. Elas tomaram conhecimento da trajetória formativa da pesquisadora que coletou as narrativas, dos objetivos do estudo e dos procedimentos da investigação e demonstraram interesse pela temática.

A garantia do sigilo e da confidencialidade das informações também foi mencionada, ficou decidido que as docentes seriam identificadas no texto com a letra D seguida de um número (D1 a D6). Somente após a aceitação das docentes para a realização da pesquisa o processo de coleta de dados foi iniciado, em horários previamente agendados.

O texto encontra-se organizado em três seções que analisam as categorias emergentes, além das considerações iniciais, percurso metodológico e considerações finais. A primeira seção apresenta a categoria "significados de ser professora". A seção seguinte aborda as considerações sobre "a escolha profissional". Na terceira seção explicita-se a forte tendência acerca da "vocação para o exercício da profissão docente". Por fim, é proposta a ação de (re) pensar a profissionalização docente com o intuito de desconstruir a ideia de dom e sacerdócio para que o docente cumpra o seu trabalho.

\section{Caminho metodológico percorrido}

Esta investigação possui abordagem qualitativa, isto é, aprofunda-se, conforme Minayo (2002, p. 10) "no mundo dos significados das ações e relações humanas". O foco é a compreensão e a interpretação da realidade. Ainda conforme a autora, a organização do 
processo de pesquisa deve obedecer a três principais dimensões, a saber: as escolhas teóricas, as técnicas e a criatividade do pesquisador.

Nesse sentido, tendo em vista as escolhas teóricas feitas por nós, bem como o objetivo de analisar as concepções das professoras colombianas sobre a profissão docente, chegamos ao consenso de que seria adequado realizar uma pesquisa do tipo estudo de caso (BOGDAN; BIKLEN, 1994; YIN, 2005). Essa decisão se justifica por conta da nossa pretensão de analisar em profundidade uma experiência específica.

O percurso trilhado pela pesquisa qualitativa faz emergir aspectos subjetivos e são utilizadas quando a busca é feita no sentido de captar percepções e entendimento sobre a natureza geral de determinada questão, o que dá margem à interpretação. Nesta pesquisa, o ponto de partida para as inferências foram as conversas realizadas com as seis professoras colombianas em exercício, tendo como principal critério para a escolha das participantes, a atuação em uma escola primária há mais de cinco anos.

O instrumento de produção e coleta de informações utilizado foi a conversa interativoprovocativa, realizada presencialmente por uma das pesquisadoras do presente estudo. Vale destacar que a conversa interativo-provocativa está apoiada na pesquisa qualitativa, que destaca as conversações como modo de expressão dos participantes e é um instrumento de produção de informações criado e utilizado pelo professor Dr. Claudio Pinto Nunes, da Universidade Estadual do Sudoeste da Bahia (UESB). O instrumento foi criado e utilizado durante sua pesquisa de doutoramento, intitulada "Ciências da educação e prática pedagógica: sentidos atribuídos por estudantes de Pedagogia”.

De acordo com Nunes (2011, p. 62), a conversa interativo-provocativa é assim denominada "por entender a necessidade de evidenciar a natureza interativa dessas conversas, do mesmo modo e com a naturalidade semelhante àquela que ocorre em qualquer conversa que as pessoas estabelecem no seu cotidiano, independente de estarem ou não participando de uma pesquisa.”.

Após a transcrição, as respostas das conversas foram analisadas na língua original em que foram concedidas e, logo após, traduzidas e categorizadas, observando as ideias convergentes ou divergentes, as quais, em determinados momentos, inclinam-se na direção de responder a questão previamente formulada. As pesquisadoras se atentaram para as distintas percepções e reflexões sobre o fenômeno analisado, com vistas a discutir, entrar em consenso e validar o texto final. 
Serão apresentados, posteriormente, os resultados da análise das conversas interativoprovocativas realizadas com as professoras colombianas que se dispuseram a colaborar com a pesquisa. As perguntas que direcionaram a conversa interativo-provocativa foram: "Para você, o que significa ser docente?”, “Qual foi sua principal motivação para ser professora?”, "Na sua concepção, quais os elementos necessários para ser docente?" "Cite cinco palavras que lhe remetem a 'ser professora". O processo analítico, que respondeu à questão de pesquisa previamente formulada, originou três categorias que serão discutidas a seguir.

Vale ressaltar que, por se tratar de uma pesquisa realizada com seres humanos, houve a necessidade de submeter o projeto ao Comitê de Ética em Pesquisa. O número do protocolo para apreciação é CAAE: 45524321.4.0000.0055.

\section{Significados de "ser professora"}

A análise das conversas com as docentes investigadas revelou pontos comuns no que se refere aos significados de ser professora, além de evidenciar a consciência que elas têm quanto à responsabilidade de formar pessoas, visto que suas ações influenciarão diretamente a vida dos estudantes. Conforme Pimenta (2012, p. 18) "professorar não é uma atividade burocrática para a qual se adquire conhecimentos e habilidades técnico-mecânicos." Mais do que adquirir conhecimentos e habilidades, o professor ensina como contribuição ao processo de humanização dos estudantes.

Para a docente D3 ser professora é "uma oportunidade maravilhosa de formar, influenciar e impactar a vida dos estudantes." Ela destaca o lado positivo de ser formadora e se considera responsável pelo sucesso dos estudantes que fazem parte de sua turma. Abnegação, paciência, amor, responsabilidade e transcendência foram os termos que afirmou lhe remeter à profissão docente.

Na mesma linha de pensamento da colega de profissão, a docente D2 afirmou que:

ser professora é uma grande responsabilidade pela formação que se dá aos estudantes para o melhor desempenho na vida. Por outro lado é uma grande dignidade que é reconhecida por diversas instituições a fim de alcançar os mais altos escalões que a aprendizagem requer, adequada para que o estudante atue na sociedade com responsabilidade.

Corroboramos com Lengert (2011, p. 18) ao afirmar que "[...] o professor acredita poder melhorar a realidade através do trabalho. Ele acredita nisso e investe na construção de 
um ideal. Ele trabalha arduamente além das horas remuneradas [...]. Há um grande empenho, por parte dos professores, em ver os estudantes progredindo. Ademais, as docentes relataram se sentir responsáveis pelo sucesso e pelo fracasso das turmas, já que o trabalho que realizam é direcionado para que o processo de ensino-aprendizagem tenha resultados positivos. Apesar disso, um fator preocupante e válido de ser discutido é o fato de a expectativa do profissional nem sempre ser correspondida, o que pode acontecer.

Lengert (2011, p. 18) complementa: "a possibilidade de o professor criar e de transformar seres humanos pode levá-lo tanto a uma realização plena, como também a uma profunda frustração.” E essa decisão é tão relevante quanto pensar nos frutos positivos do processo de ensino-aprendizagem, pois, em alguns casos, quando o docente percebe que falhou no exercício de sua prática a sensação de impotência, fracasso e até mesmo de derrota, pode fazer com que ele se desestabilize, ainda que tenha uma carreira consolidada.

A docente D5 resumiu sua narrativa com a seguinte declaração: "ser professora é contribuir com um grão de areia para uma sociedade melhor." De acordo com esta professora, por menor que seja a contribuição, juntos, os professores, sejam eles mais experientes ou iniciantes, ganham mais força e podem realizar mudanças positivas e significativas na vida dos estudantes.

Sobre essa questão, Tardif e Lessard (2011, p. 48) pontuam que "a organização do trabalho na escola é, antes de tudo, uma construção social contingente oriunda das atividades de um grande número de atores individuais e coletivos, que buscam interesses que lhes são próprios, mas que são levados, por diversas razões, a colaborar numa mesma organização.” Nesse sentido, é notório que, ao unir forças em prol de oferecer uma formação sólida aos estudantes, as possibilidades de elevar os índices de qualidade da educação são muito maiores.

Há, também, por parte da docente D5, uma grande inquietude com a formação de estudantes cidadãos, que saiam da escola com condições de se posicionar socialmente e compromissados na construção de uma sociedade mais justa. Ser professora, para ela, envolve o compromisso com “dar um 'giro' na vida dos alunos, para que futuramente sejam cidadãos de bem." Nessa senda, os termos compromisso, ternura, responsabilidade e paixão foram escolhidos pela referida professora para mencionar a sua atuação docente. 
Ao relacionar o "ser professora" com os termos amor, valores e conhecimento, a docente D6 considera que é impossível atuar sem que haja um profundo querer dentro da profissão. Em suas palavras:

Ser professor é uma arte na qual se deve colocar o coração para poder ensinar aos estudantes que estão sendo criados sozinhos, já que os pais estão trabalhando, que somos o exemplo mais próximo de autoridade e exemplo, e ainda mais porque para muitos deles, a escola é o único lugar onde são levados em conta. (DOCENTE D6)

Conforme a docente D1, ser professora "é uma experiência maravilhosa, ter a oportunidade de trabalhar com crianças especialmente é muito gratificante, uma aventura maravilhosa, como uma roleta russa, muitas emoções. Penso que é a melhor profissão de todas." Para ela, as expressões que lhe remetem imediatamente à docência são alegria, criatividade, sonhos, paciência e constância. Suas falas durante a conversa interativoprovocativa revelam que consegue ser rigorosa sem deixar de ser alegre e empática com os alunos.

Sobre essa questão, Freire (1996, p. 142) afirmou que:

A atividade docente de que a discente não se separa é uma experiência alegre por natureza. E falso também tomar como inconciliáveis seriedade docente e alegria, como se a alegria fosse inimiga da rigorosidade. Pelo contrário, quanto mais metodicamente rigoroso me torno na minha busca e na minha docência, tanto mais alegre me sinto e esperançoso também. A alegria não chega apenas no encontro do achado, mas faz parte do processo da busca. E ensinar e aprender não podem dar-se fora da procura, fora da boniteza e da alegria.

A alegria mencionada diversas vezes pela professora durante a conversa é um dos indícios de como os seus "modos de fazer" têm refletido na relação que ela estabelece com as turmas e com os seus próprios saberes, os quais, conforme Tardif (2014, p. 11) são os saberes "dela", relacionados com a própria pessoa, "[...] com sua experiência de vida e com a sua história profissional, com as suas relações com os alunos em sala de aula".

Por fim, a docente D4 expressa, em suas respostas, uma grande inclinação para a ideia da Educação enquanto promotora de valores, e demonstra que se sente responsável por não apenas escolarizar as crianças, mas também prepará-las para a vida. Ser professora para ela é "formar crianças de maneira integral" e os termos que the remetem a sua atuação pedagógica são "O Todo Poderoso, sabedoria, entrega e vocação". 


\section{OO DEVIR EDUCAÇÃO}

ISSN: 2526-849X

O que se pôde analisar a partir das narrativas das professoras entrevistadas é que os significados da docência estão ligados, principalmente, à responsabilidade no processo formativo dos estudantes, uma vez que uma boa orientação escolar deixa marcas positivas, tanto na vida dos discentes quando na vida dos discentes. Essa reflexão vai ao encontro da visão de Imbernón (2011, p. 29) "ser um profissional da educação significará participar na emancipação das pessoas.”.

Os termos mencionados pelas professoras para caracterizar a profissão evidenciaram que a concepção de "ser professor" é plural e permitiram também identificar algumas concepções marcadas pelo senso comum, como por exemplo, a associação feita do "ser professor" a "vocação" e ao "O Todo Poderoso". Assim como Oliveira (2021, p. 74) consideramos "arriscado reforçar a ideia de que o professor nasce com um dom, pronto para exercer um sacerdócio como professor, visto que, a história de vida dos professores é mediadora entre os saberes e o exercício profissional que requer um longo processo de socialização.”.

As respostas apontam que as professoras acreditam ter uma função fundamental no processo de construção social dos estudantes, visto que exercem grande influência em suas vidas, além de fornecer bases para a formação de cidadãos que contribuam diretamente para o desenvolvimento da sociedade. Esse compromisso é firmado por elas desde o momento da escolha em atuar como professoras, categoria que será discutida no seguinte tópico.

\section{A escolha profissional}

O presente estudo evidenciou que a escolha pela profissão pode ser determinada por aspectos pessoais, familiares, sociais e, até mesmo, educacionais. Os motivos de opção por atuar na docência perpassam pela identificação com as questões educativas, as experiências vivenciadas, as influências diretas ou indiretas, bem como as questões profissionais.

Questionadas sobre a decisão por se tornarem professoras, os relatos coadunam no que se refere às influências, mesmo que indiretamente, de familiares e pessoas próximas. As participantes demonstraram que sempre estiveram de alguma forma envolvidas com as questões ligadas a Educação. A docente D1 afirmou: "Creio que sempre tive a vocação, sou a mais velha dos quatro filhos e recordo que sempre brinquei de ser professora e meus irmãos eram os estudantes. Então isso foi estimulante.”. 
No caso da docente D3, ela relatou: "Desde criança eu queria ensinar. Meu pai foi zelador de escolas, cresci em algumas delas, observando e desfrutando da vocação das professoras que eu via dando aulas." A maioria das participantes demonstrara que se sentiam inspiradas ao ver a dinâmica das escolas, seja por acompanhar um familiar que desempenhava outras funções na escola, seja por auxiliar alguém próximo que atuava na sala de aula.

De acordo com Tardif e Raymond (2000, p. 219), "a vida familiar e as pessoas significativas na família aparecem como fonte de influência muito importante que modela a postura da pessoa toda em relação ao ensino." Em conformidade com essa ideia, as participantes evidenciaram em seus relatos que as questões familiares foram, para elas, verdadeiros estímulos para que se tornassem professoras, pois de alguma maneira foram tocadas pelas vivências.

O convívio com a família, a orientação em atividades escolares, ou até mesmo o desejo de compartilhar conhecimentos oportunizou uma inclinação para a escolha da docência desde cedo. Esses fatores vão ao encontro de pesquisas desenvolvidas por Tardif e Lessard (1996, 2000), os quais constataram que "vários professores falaram da origem infantil de sua paixão e de sua opção pelo ofício de professor [...] muitos professores, especialmente mulheres, falaram da origem familiar da escolha de sua carreira [...] porque vinham de uma família de professores", o que coaduna com a seguinte fala:

Desde criança quis ser professora, minha mãe era professora e nos ensinou que em suas mãos estava o futuro da sociedade e por isso ela tinha que ensinar valores, compartilhar para ajudar o outro a sonhar, mas ainda mais para realizar nossos sonhos, já que tudo é possível se lutarmos tomando como guia nosso criador. (DOCENTE 6)

Outro fator preponderante nos relatos das professoras foi relacionado à escolha pelos estudos na "Escola Normal" no sistema de ensino colombiano, que conforme Rativa-Velandia (2018, p. 12) tinha como objetivo "la formación de los maestros para enseñar en las escuelas que se abrirían”. Os relatos ratificam:

Decidi ser professora com aproximadamente 10 anos, quando tive que colaborar com as tarefas para meus 4 irmãos. Além disso, porque tive a oportunidade de me matricular em uma escola normal. (DOCENTE 5)

Decidi ser professora quando tive que escolher a classe de bachillerato que estudaria. Isso foi decisivo para sustentar minhas convicções quanto a trabalhar como professora. (DOCENTE 4) 


\section{OO DEVIR EDUCAÇÃO}

ISSN: 2526-849X

A docente D2 registrou: “decidi ser professora como uma etapa na realização de meus estudos profissionais e também por vocação. Ajudar as crianças a defender seus direitos e ajudá-las emocionalmente para o progresso de suas vidas é gratificante.” Podemos depreender da fala da professora que há, de modo geral, uma forte propensão a se referir à docência como um ato vocacionado e é perceptível a dificuldade que existe de desmistificar essa ideia tão presente nos discursos individuais - e coletivos-, visto que, como bem explicita Arroyo (2000, p. 33)

Por mais que tentemos apagar esse traço vocacional, de serviço e de ideal, a figura de professor, aquele que professa uma arte, uma técnica ou ciência, um conhecimento, continuará colada à ideia de profecia, professar ou abraçar doutrinas, modos de vida, ideais, amor, dedicação. Professar como um modo de ser. Vocação, profissão nos situam em campos semânticos tão próximos das representações sociais em que foram configurados culturalmente. São difíceis de apagar no imaginário social e pessoal sobre o ser professor, educador, docente.

Nessa mesma linha de raciocínio, em seu estudo sobre a profissionalização docente, Lengert (2011, p. 17) é categórico ao afirmar que a função dos professores "mantém o status vocacional e continua a fazer parte de um rol de profissões que a coloca ao lado de atividades missionárias." Destaca ainda que Codo (1999) compara o professor ao sacerdote, ao mencionar que ambos têm seus ritos e sua vocação. No geral, ele tem vontade de promover algo em prol do outro, de também se sentir realizado com a realização do sonho do outro.

Vale ressaltar que a inserção no mercado de trabalho não foi considerada como fator de escolha da profissão, pois a maioria priorizou a afinidade com a área de atuação, independente das oportunidades futuras para atuar como professoras e são convictas ao afirmar que ainda hoje mantêm a opção profissional, mesmo sabendo que podem abandonar a área e recomeçar.

No conjunto de relatos há uma forte tendência relacionar a labuta na sala de aula ao fato de estarem destinadas a atuar como professoras, e, consequentemente, relacionar a profissão a um chamado, a uma vocação, categoria emergente que será discutida no próximo tópico.

\section{A vocação para o exercício da profissão docente}


As conversas interativo-provocativas renderam um material muito mais vasto do que imaginávamos, pois, livres para falar, as professoras se expressaram de maneira espontânea, sem receios de julgamentos. Foi possível atestar o que Nunes (2011, p. 45) afirmou sobre as conversas, as quais "possibilitam ao pesquisador ter acesso à expressão subjetiva e individual dos sujeitos".

Em posse dos relatos obtidos nas conversas, verificamos a predominância de uma categoria que demandou maior atenção no presente estudo: a vocação como um dos elementos indispensáveis para o exercício da profissão docente.

É importante ter vocação para trabalhar com crianças, ser muito ético, de ter claro que a única profissão que não se pode equivocar é a de professor. Por exemplo, se na vida profissional de um arquiteto cai a ponte e um edifício e tudo bem, depois volta e faz novamente. Mas não se pode equivocar na formação de um ser humano. (DOCENTE 1, grifos nossos)

A vocação é muito importante, há melhor desenvolvimento e o que se realiza se compreende muito melhor. Os conhecimentos de determinados campos e diferentes áreas fazem parte do interesse do ensino. Ter alto espírito de dedicação, não se desviar de seus objetivos e manter sempre uma boa relação entre professor e aluno é muito importante para a aprendizagem, comportamento e a parte emocional. (DOCENTE 2, grifos nossos)

Acho que eles devem responder de acordo com o perfil. Elementos: amor pela profissão e vocação, pois é uma profissão que tem muita demanda, mas nosso esforço não é reconhecido, então o melhor pagamento a todo o nosso esforço é o sorriso de uma criança quando ele consegue superar suas dificuldades. O professor deve saber combinar valores, conhecimentos, sentimentos, normas, harmonia para que as crianças sejam felizes em sala de aula e, portanto, o estudo seja um prazer e não um fardo. (DOCENTE 6, grifos nossos)

Esse conjunto de relatos revela a ideia enraizada de que os professores são seres que nasceram predestinados e prontos para atuar na sala de aula, que possuem um "talento", por isso devem estar na área da Educação e são capazes de realizar atos divinos com os estudantes. O agravante de alimentar a ideia do sacerdócio é que haja certa dificuldade de encarar a profissão como uma construção social que requer anos de estudo e dedicação. 


\section{OO DEVIR EDUCAÇÃO}

ISSN: 2526-849X

Outro aspecto mencionado foi a ética, já que, segundo as participantes, lidar com vidas requer, além de muita responsabilidade, uma postura adequada, pois certamente elas servirão de "modelos, exemplos" para os estudantes.

A docente D5 destaca que "para o exercício da profissão, se deve ser tolerante, sincero, responsável e ético." No que se refere ao destaque dado pela professora à questão ética, é notório que esse pensamento está correlacionado à concepção de Freire (1996, p. 33), ao afirmar que "estar longe ou pior, fora da ética, entre nós, mulheres e homens é uma transgressão. É por isso que transformar a experiência em puro treinamento técnico é amesquinhar o que há de fundamentalmente humano no exercício educativo: o seu caráter formador.".

Durante a conversa, a professora demonstrou grande afinidade com as ideias propostas pelas ideias freireanas, pois suas falas se direcionavam para a importância de valorizar uma escola com ideais mais humanos, que desenvolvesse práticas de empatia entre os estudantes, os quais, colocados em posição de igualdade, fossem orientados a agir conforme os princípios éticos e democráticos. E é justamente essa a proposta da Pedagogia da Autonomia sugerida por Freire (1996) em sua obra.

Para a docente D4, é necessário que o professor tenha "vocação, todos os valores, exemplo, conhecimentos em psicologia, didática e conhecimentos pedagógicos". A fala da participante deixa pistas relacionadas à mobilização dos diversos saberes para a atuação profissional, somada à consciência quanto a importância do preparo pedagógico que devem ter para lidar com as situações que permeiam a dinâmica escolar. Sobre essa questão, Tardif e Raymond (2000, p. 214) pontuam:

Os professores utilizam constantemente seus conhecimentos pessoais e um saber-fazer personalizado, trabalham com os programas e os livros didáticos, baseiam-se em saberes escolares relativos às matérias ensinadas, fiam-se em sua própria experiência e retêm certos elementos de sua formação profissional.

Nessa mesma linha de raciocínio, conforme destacam Oliveira e Barreto (2020, p. 09)

os elementos que compõem a natureza dos saberes docentes são provenientes de diferentes períodos de socialização que ocorrem dentro de um processo espaço-temporal, e traz com eles elementos plurais, heterogêneos, humanos, personalizados e situados, configurando a natureza desses saberes como sendo social.

Revista Devir Educação, Lavras, vol.5, n.1, p.63-80, jan-jun/ 2021 
Dessa forma, apoiadas nas ideias dos referidos autores, entendemos que os professores utilizam diversos saberes no decorrer de sua trajetória profissional, que se originam na prática cotidiana, os quais servem de base para o ensino e de apoio para a solução de problemas. A narrativa da professora também está em conformidade com o que Oliveira e Barreto (2020, p. 07) assinalaram sobre a importância do professor "ter consciência de que ensinar não envolve apenas os conhecimentos específicos que são adquiridos ao longo do tempo, mas também saberes pedagógicos, didáticos e a própria experiência.”.

No que se refere a vocação para o magistério, Arroyo (2000) aponta que ela não seria tão somente um resquício de uma visão religiosa que permanece viva. Uma possibilidade é que essa ideia poderia estar imbricada no próprio conceito de profissão, de professor, de profecia. E, a partir daí, caminharíamos para o espantoso descrédito, presente na nossa profissão, o que gera grande dificuldade de conquistar o profissionalismo necessário e a valorização financeira. Nesse sentido, considerar indispensável que o professor tenha a docência como uma espécie de chamado é limitar uma profissão que, assim como as demais, exige preparo, formação.

Krentz (1986, p. 16) também buscou desmistificar a ideia do magistério como um sacerdócio. Para ele, essa concepção "dificulta a participação efetiva dos professores na organização da categoria profissional [...], cria a resistência da própria sociedade [...] pois lhe cobra uma postura vocacional, de doação". Nessa senda, percebemos o quanto é perigoso fortalecer a ideia de que o professor é pura e simplesmente vocacionado, predestinado a atuar na escola, pois, independente de alguns profissionais acreditarem que nasceram para lecionar é importante que eles tenham uma formação sólida que lhes permita aprender sobre seu ofício e sobre as ferramentas que encontram a sua disposição no decorrer da sua trajetória docente.

Ademais, Oliveira (2021, p. 106) cita que "O professor carrega consigo diversas marcas provenientes dos processos de ensino-aprendizagem, os quais foram vivenciados em sua trajetória, tanto na condição de aluno quanto na condição de professor em exercício”. Assim, é importante considerar que através de experiências adquiridas no cotidiano escolar, o professor constrói saberes significativos e indispensáveis para sua prática docente.

No entendimento de Tardif (2014) é impossível tratar dos saberes sem relacioná-los com os condicionantes e com o contexto do trabalho, uma vez que estão relacionados com a 
pessoa, a identidade, as experiências de vida e com sua história profissional, além das relações estabelecidas com os alunos em sala de aula e com os demais atores da escola.

A única participante que mencionou a importância de uma formação acadêmica adequada foi a docente D3. Ao relatar que considera indispensável para a sua atuação docente “formação acadêmica apropriada, vocação e amor", esta docente demonstra a consciência de que, além de ter predisposição para ensinar, o profissional precisa ter clara a importância de investir no processo formativo, fator indispensável para um exercício profissional comprometido com a qualidade da Educação.

\section{(Re) pensar a profissionalização docente}

Ao analisar as narrativas das professoras colaboradoras da presente pesquisa, reforçamos a proposta de repensar as questões que envolvem a profissionalização docente, visto que, conforme Schon $(1992 ; 1998)$ ser um profissional implica dominar capacidades e habilidades especializadas que oportunizam competência para determinado trabalho.

Embora existam muitos professores que demonstram ter grande afinidade e, por vezes, admitam ter certa predisposição para lecionar, reforçar a ideia de que os educadores nascem com um dom, vocacionados, ou até mesmo que lecionam por conta de uma espécie de “chamado" é - mesmo que sem ter a pretensão - desvalorizar o trabalho ligado à docência, pois os professores vivem em constante aprendizagem: eles aprendem a aprender, a ensinar, bem como aprendem, diuturnamente, sobre seu próprio ofício.

Para Imbernón (2011, p. 30) “a profissão docente comporta um conhecimento pedagógico específico, um compromisso ético e moral e a necessidade de dividir a responsabilidade com outros agentes sociais". Nesse sentido, acreditamos que a discussão sobre a formação e profissionalização docente pode ressignificar diversos conceitos que, por vezes, confundem o ser e o fazer na docência e levam os professores a relacionar sua escolha e exercício profissional, principalmente, a aspectos que não contemplam a dimensão formativa imprescindível para a atuação dos professores.

Conforme destacam Oliveira e Barreto (2020, p. 02)

A responsabilidade do sucesso ou fracasso do processo educativo não pode ser atribuída exclusivamente ao/a professor/a, no entanto, devemos considerar o investimento na formação docente como uma importante variável que interfere de maneira direta na qualidade do ensino e, consequentemente, na aprendizagem dos/as estudantes. 
Dessa forma, ao pensar na relevância da formação e das construções que fazem parte da dinâmica da vida laboral dos professores, corroboramos com Lengert (2011, p.19) ao afirmar que "a escolha por ser professor é uma construção e não pode ser encarada apenas como uma vocação individual numa progressão linear e sucessiva".

Vale ressaltar que a década de 1980 trouxe um grande marco para as discussões acerca da profissionalização do ensino que foi reconhecer que existem saberes específicos que caracterizam a profissão docente, os quais são desenvolvidos pelos professores tanto no seu processo de formação para o trabalho quanto no cotidiano de suas atividades como docentes.

Essa é, sem dúvida, uma das maneiras de (re) pensar e (re)significar a profissionalização docente, sem perder de vista o lugar que a formação continuada ocupa, a qual

[...] deve ser concebida como reflexão, pesquisa, ação, descoberta, organização, fundamentação, revisão e construção teórica e não como mera aprendizagem de novas técnicas, atualização em novas receitas pedagógicas ou aprendizagem das últimas inovações tecnológicas. (GADOTTI, 2003, p. 41).

Em consonância com essa ideia, Lengert (2011, p. 21), defende que "existe, sim, uma formação que pode preparar adequadamente a professora e o professor, e também é possível falar de uma formação que pode acompanhá-lo(a) durante o desenvolvimento de suas carreiras.”. Por este motivo é relevante defender que hajam espaços para reflexões e debates nos cursos de graduação e nos Programas de Pós-Graduação, com vistas a buscar uma formação coerente, que contemple o entendimento da identidade pessoal e profissional, as quais, conforme os estudos de Tardif (2012) vão sendo pouco a pouco construídas e experimentadas.

\section{Palavras (in) conclusivas}

A investigação realizada permitiu-nos analisar e, consequentemente, compreender as concepções de um grupo de professoras colombianas acerca da profissão docente. Os resultados apontaram para o entendimento de que a vocação é, para as participantes, um dos elementos indispensáveis para o exercício da sua profissão. É importante levar em 


\section{ODEVIR EDUCAÇÃO}

ISSN: 2526-849X

consideração que uma atividade de tão grande relevância como ensinar exige anos de formação e desenvolvimento de habilidades e competências específicas para a atuação docente. Não é suficiente que tenhamos boa vontade e disposição para nos considerarmos professores/as.

Assim como nas demais profissões, passamos por um processo formativo árduo que independente da instituição ou modalidade de estudo requer conhecimento teórico, científico, metodológico, didático, entre outros. Dessa forma, o estudo aponta para a necessidade de (re)pensar a profissionalização docente e, consequentemente, desmistificar a ideia da docência como atividade vocacionada.

Entendemos que a pesquisa é um processo incessante de produção e análise de informações, e, portanto, constitui um ato que envolve indagação, questionamento, aprofundamento e a socialização de conhecimentos. Seguindo essa linha de compreensão, consideramos que a presente investigação contribui para evidenciar a importância de pesquisas que visem a compreensão das concepções de professores sobre os elementos que condicionam seu exercício profissional, pois esse exercício está diretamente relacionado à qualidade da Educação.

Ademais, é sempre relevante pensar nas possibilidades de ressignificação da identidade do professor, visto que esse movimento pode oferecer significados coerentes para o docente e para as dinâmicas que fazem parte de sua profissão. Apoiadas nos referenciais teóricos estudados, compreendemos que novas rotas precisam ser feitas e refeitas. Ainda há muito o que ser desvelado, mas este texto, sem dúvida, sinaliza possibilidades para futuras investigações.

\section{Referências}

ARROYO, Miguel. Ofício de Mestre: imagens e auto-imagens. Petrópolis, RJ: Vozes, 2000.

BOGDAN, Robert.; BIKLEN, Sari. Investigação Qualitativa em Educação. Porto: Porto Editora , v. Colecção Ciências da Educação, 1994.

CODO, Wanderley. Educação: carinho e trabalho: Burnout, a síndrome da desistência do educador, que pode levar à falência da educação. Petrópolis: Vozes, 1999.

DUBAR, Claude. A socialização: construção das identidades sociais e profissionais. São Paulo: Martins Fontes, 2005. 
FREIRE, Paulo. Pedagogia da autonomia: saberes necessários à prática educativa. 25. ed. São Paulo: Paz e Terra, 1996.

GADOTTI, Moacir. Boniteza de um sonho: ensinar-e-aprender com sentido. Novo Hamburgo, RS: Feevale, 2003.

IMBERNÓN, Francisco. Formação docente e profissional: formar-se para a mudança e a incerteza. 9. ed. São Paulo: Cortez, 2011.

KRENTZ, Lúcio. Magistério: vocação ou profissão? Educação em Revista, Belo Horizonte, p. 12-16, jun $1986 . \quad$ Disponivel em: <http://educa.fcc.org.br/scielo.php?script=sci_arttext\&pid=S010246981986000100004\&lng=pt\&nrm=iso>. Acesso em 20 out. 2014. Acesso em: 13 dez. 2020

LENGERT, Rainer. Profissionalização docente: entre vocação e formação. La Salle - Revista de Educação, Ciência e Cultura, Canoas/RS, 16, jul/dez 2011. 11-23. Disponível em: https://revistas.unilasalle.edu.br/index.php/Educacao/article/view/195 Acesso em: 15 dez. 2020

NUNES, Claudio Pinto. As Ciências da Educação e a prática pedagógica: sentidos atribuídos por estudantes do curso de Pedagogia. 2010. 192f.. Tese (Doutorado em Educação) - Universidade Federal do Rio Grande do Norte, Natal, 2010.

OLIVEIRA, Edmila Silva de. Representações sociais sobre a docência superior nos cursos de pedagogia da UESB: saberes e dimensões. 2021. 125 f. Dissertação (Mestrado em Educação) - Universidade Estadual do Sudoeste da Bahia, Programa de Pós-Graduação em Educação - PPGED, Vitória da Conquista, 2021.

OLIVEIRA, Edmila Silva de; BARRETO, Denise Aparecida Brito. Contemporary studies on knowledge, teaching in higher education and social representations in Brazil. Journal of Research and Knowledge Spreading, Arapiraca, Alagoas, v. 1, n. 1, dez. 2020. Disponível em: https://seer.ufal.br/index.php/jrks/article/view/11585/8115 Acesso em: 28. Nov. 2020.

PIMENTA, Selma Garrigo. Saberes pedagógicos e atividade docente. 8. ed. São Paulo: Cortez, 2012.

RÁTIVA-VELANDIA, Marlén. Escuela Normal colombiana frente a las disposiciones legales. Tensiones pedagógicas y administrativas. Praxis, p. 9-24, 2018. Disponível em: https://doi.org/10.21676/23897856.2537. Acesso em: 28. Nov. 2020.

SCHON, Donald. La formación de profesionales reflexivos. Barcelona: Paidós, 1992.

SCHON, Donald. El profesional reflexivo. Barcelona : Paidós, 1998. 
TARDIF, Maurice. Saberes docentes e formação profissional. 17. ed. Rio de Janeiro: Vozes, 2014.

TARDIF, Maurice; LESSARD, Claude. O trabalho docente: elementos para uma teoria da docência como profissão de interações humanas. 6. ed. Rio de Janeiro: Vozes, 2011.

TARDIF, Maurice; RAYMOND, Danielle. Saberes, tempo e aprendizagem do trabalho no magistério. Educação \& Sociedade, Campinas, v. 21, n. 73, p. 209-244, dez. 2000.

YIN, Roberto. K. Estudo de caso: planejamento e métodos. 3. ed. Porto Alegre: Bookman, 2005.

Recebido em 01/02/2021

Aprovado em 19/04/2021 